\title{
Development of a Vibration Powered Micro Generator and its Application to Harvest the Vibration Energy of the KRI KKP-811's Engine
}

\author{
Harus L.G., Wiwiek Hendrowati and Rahmat Susanto \\ Department of Mechanical Engineering, Faculty of Industrial Technology ITS, Surabaya \\ Email: masharus@me.its.ac.id
}

\begin{abstract}
Vibration energy harvesting has been receiving a considerable amount of interest as a means of powering wireless sensors and low-power devices. In this paper, an energy harvester is presented to convert ambient mechanical vibration into electrical energy employing magnetoelectric generator. The harvester uses single magnet-spring attached on the coil. When the harvester is excited, the magnet moves relative to the coil, undergoes magnetic field variations and produces a power output. To obtain a maximum power output, the mass of magnet is varied. The magnetoelectric generator with various masses of magnets was tested by a harmonic exciter with various frequencies and amplitudes. The one with maximum power output was then applied to harvest the ambient vibration energy of KRI KKP-811's Engine. The results show that this prototype can harvest maximum energy of $2 \mu \mathrm{W}$ when it is placed at the base/foundation of the engine.
\end{abstract}

Keywords: Vibration, wasted energy, energy harvester, micro generator, magnetoelectirc, electricity.

\section{INTRODUCTION}

Recently, energy harvesting has emerged as a solution for powering autonomous sensor nodes to increase their expected lifetimes. In wireless sensor applications where photovoltaic, optical, thermal, or electrical energy sources are not practical or available, energy harvesting devices that convert kinetic energy into electrical energy have attracted much interest. A variety of micro-machined vibration driven generators using electromagnetic principles to convert the kinetic energy of a suspended mass into electrical energy, are being studied for powering wireless sensor nodes. With the decreasing size and power requirements of wireless sensor networks, there exists a significant driver to miniaturize the size of the power generators.

Beeby et al. [1] have reviewed the state of the art of vibration powered generators in detail. In the following, we briefly review the main research results relating to electromagnetic devices. In their recent work, Beeby et al. [2], present working of a small (volume-0.1 cm3) electromagnetic generator using moving $\mathrm{NdFeB}$ magnets on beryllium-copper beam, placed around a fixed wire wound coil. They report a maximum power of $46 \mathrm{~W}$ from the device in a $4 \mathrm{k}$ load from $0.59 \mathrm{~m} / \mathrm{s} 2$ acceleration at a resonant frequency of $52 \mathrm{~Hz}$. Previously, El Hami et al. [3] presented results from an electromagnetic power generator comprising of cantilever beam with a pair of $\mathrm{NdFeB}$ magnets with wire-wound coil fixed between the poles of the magnets. They reported $1 \mathrm{~mW}$ of power generated for a $0.24 \mathrm{~cm} 3$ volume at a frequency of $320 \mathrm{~Hz}$. Further, Glynne-Jones et al. [4] demonstrated working of an assembled electromagnetic power generator, using fixed bulk magnets and moving wire-wound coil fixed on a stainless steel beam. The generator produced a power of $180 \mathrm{~W}$ at a frequency of $322 \mathrm{~Hz}$, acceleration of $2.7 \mathrm{~m} / \mathrm{s} 2$ and had a volume of $0.84 \mathrm{~cm} 3$. In recent work, Serre et al. [5] used a moving $\mathrm{NdFeB}$ magnet on a polyamide film and a fixed planar coil made of aluminum layer. The device produced a power of $200 \mathrm{nW}$ at a resonant frequency of $360 \mathrm{~Hz}$ for a displacement of $6.8 \mathrm{~m}$.

In other work, Mizuno et al. [6] described the use of an integrated coil on a cantilever beam with fixed $\mathrm{NdFeB}$ magnets. They predicted a maximum power of $0.4 \mathrm{nW}$ for a volume of $2.1 \mathrm{~cm} 3$ at a frequency of $700 \mathrm{~Hz}$ and acceleration of $12.4 \mathrm{~m} / \mathrm{s} 2$. A silicon-based generator was reported by Kulah and Najafi [7], comprising of two separated chips combined together. They reported a maximum power of $4 \mathrm{nW}$, $25 \mathrm{~Hz}$ frequency and volume of $2 \mathrm{~cm}^{3}$. The previous reviews made by Beeby et al. [1] show that up-todate fully micro-fabricated (i.e., micro-fabricated coils, magnets, beam and housing) electromagnetic vibration generators have not been reported.

In this paper, an energy harvester is presented to convert ambient mechanical vibration into electrical energy employing magnetoelectric generator. 
The harvester uses single magnet-spring attached on the coil. When the harvester is excited, the magnet moves relative to the coil, undergoes magnetic field variations and produces a power output. To obtain a maximum power output, the mass of magnet is varied. The magnetoelectric generator with various masses of magnets was tested by a harmonic exciter in various frequencies and amplitudes. The one with maximum power output was then applied to harvest the ambient vibration energy of KRI KKP-811's Engine.

\section{RESEARCH METHODOLOGY}

The research is divided into four steps: design, development, characterization and application:

\section{Development of the Vibration Energy Harvester}

Figure 1 shows the schematic diagram of the vibration energy harvesting mechanism. The vibration energy harvester will convert the ambient mechanical vibration resulting from machines into electrical energy employing magnetoelectric generator. The harvester uses single magnet-spring attached on the coil. When the harvester is excited, the magnet moves relative to the coil, undergoes magnetic field variations and produces a power output. The AC voltage/current is then rectified by a rectifier to produce DC voltage/current before it is stored into a storage system (battery or capacitor).

Figure 2 shows the prototype of the developed vibration energy harvester. The dimensions of the harvester is $l=130 \mathrm{~mm} ; \Pi=20 \mathrm{~mm}$ and the number of coil turns are $N=4500$. According to this prototype, the vibration energy harvester can be mathematically modelled as a mass-spring-damping system [motion of based] depicted in Figure 2, left. Based on the model, the equation of motion/vibration of the vibration energy harvester (VEH) can be expressed as:

$$
\begin{aligned}
& \ddot{m}_{\mathrm{x}}+\mathrm{c}(\dot{\mathrm{x}}-\dot{\mathrm{y}})+\mathrm{k}(\mathrm{x}-\mathrm{y})=0 \\
& m \ddot{x}+c \dot{x}+k x=c \dot{y}+k y
\end{aligned}
$$

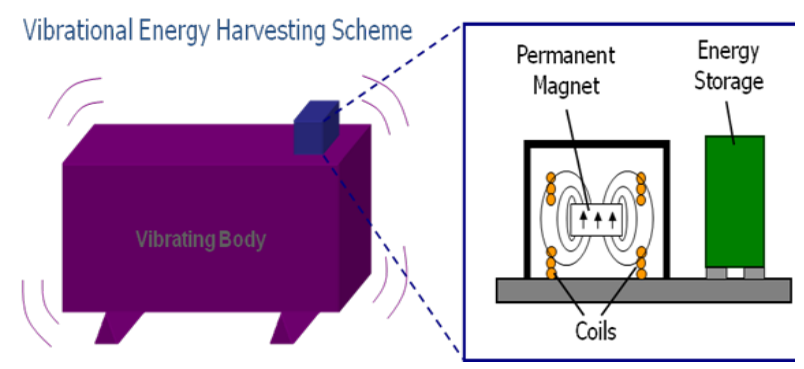

Figure 1. Schematic Diagram of the Vibration Energy Harvesting Mechanism

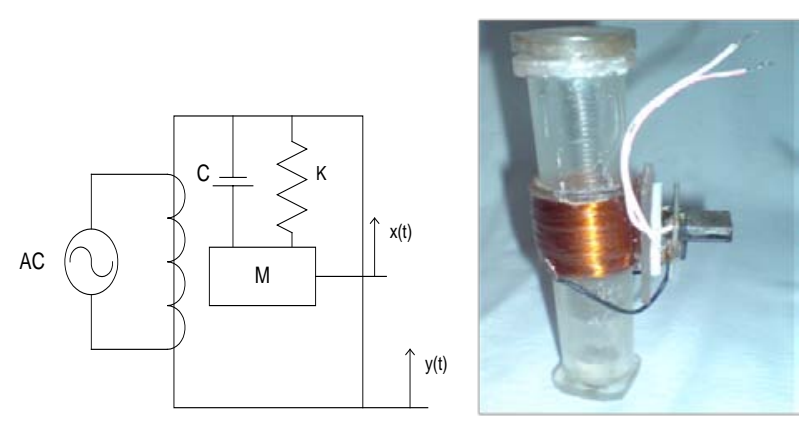

Figure 2. Prototype of the Vibration Energy Harvester

The steady state response of the system is expressed by:

$$
\begin{aligned}
& x(t)=\frac{Y o \sqrt{k^{2}+(c \omega)^{2}}}{\left[\left(k-m \omega^{2}\right)^{2}+(c \omega)^{2}\right]^{1 / 2}} \sin (\omega t-\beta-\alpha) \\
& \dot{x}(t)=\frac{\omega Y o \sqrt{k^{2}+(c \omega)^{2}}}{\left[\left(k-m \omega^{2}\right)^{2}+(c \omega)^{2}\right]^{1 / 2}} \sin (\omega t-\beta-\alpha)
\end{aligned}
$$

where:

$m$ : mass of magnet[kg]; $k$ : spring constant[N/m]; $c$ :damping constant $[\mathrm{N}-\mathrm{s} / \mathrm{m}] ; \omega$ : excitation frequency $[\mathrm{rad} / \mathrm{s}]$; and $y$ : excitation from the source of vibration

$$
\alpha=\tan ^{-1}\left[\frac{-c \omega}{k}\right] \text { and } \beta=\tan ^{-1}\left[\frac{c \omega}{k-m \omega^{2}}\right]
$$

Based on the Faraday's law, the generated voltage of the vibration energy harvester can be expressed by:

$$
E(t)=N B A \omega_{e}
$$

where:

$N$ : number of coil turn; $B$ : magnetic field [T]; $A$ : cross sectional area of the coil $\left[\mathrm{m}^{2}\right]$; and $\omega_{e}$ : magnetic flux rate $[\mathrm{cps}]$ and $\omega_{e}=\dot{x}(\mathrm{t}) / \mathrm{x}(\mathrm{t})$.

\section{Characterization of the Prototype}

To obtain a maximum power output experimenttally, the magnetoelectric generator was tested with the schematic diagram shown in Figure 3. As shown in the figure, the experimental apparatus consists of a dc electric motor $24 \mathrm{~V} 7 \mathrm{~A}$ to produce various excitation frequencies, a disc with various eccentricities to produce various excitation amplitudes, and a digital oscilloscope to measure the output voltage and current of the VEH. Table 1 and 2 shows the properties of the permanent magnet and the spring used in the generator. The dc electric motor $24 \mathrm{~V} 7 \mathrm{~A}$ was used to produce 4 excitation speeds of $\omega_{1}$ $=350 \mathrm{rpm}, \omega_{2}=484 \mathrm{rpm}, \omega_{3}=660 \mathrm{rpm}$, and $\omega_{4}=794$ rpm. The dc electric motor is connected to a disc which can produce 4 amplitudes: $A_{1}=2 \mathrm{~mm}, A_{2}=4$ $\mathrm{mm}, A_{3}=6 \mathrm{~mm}$, and $A_{4}=8 \mathrm{~mm}$. The excitation from the disc with various frequencies and amplitudes is transmitted to the vibration energy harvester by the follower (a roller bar mechanism). 
Table 1. Properties of the Magnet

\begin{tabular}{ccc}
\hline Magnet & Mass (10 $\left.\mathbf{1 0}^{-3} \mathbf{k g}\right)$ & Magnetic field (Gauss) \\
\hline $\mathrm{m}_{1}$ & 14,4 & 1200 \\
$\mathrm{~m}_{2}$ & 21,6 & 1570 \\
$\mathrm{~m}_{3}$ & 28,8 & 2010 \\
$\mathrm{~m}_{4}$ & 36 & 2440 \\
\hline
\end{tabular}

Table 2. Properties of the Spring

\begin{tabular}{cccc}
\hline Spring & $\begin{array}{c}\text { Spring } \\
\text { diameter } \\
\text { (mm) }\end{array}$ & $\begin{array}{c}\text { Spring } \\
\text { constant } \\
\mathbf{( N / m )}\end{array}$ & $\begin{array}{c}\text { Damping coeff.of } \\
\text { spring }\left(\mathbf{1 0}^{-4} \mathbf{k g} / \mathbf{s}\right)\end{array}$ \\
\hline $\mathrm{k}_{1}$ & 6,3 & 11,84 & 1,48 \\
$\mathrm{k}_{2}$ & 8 & 13,14 & 2,77 \\
$\mathrm{k}_{3}$ & 8 & 5,78 & 1,76 \\
$\mathrm{k}_{4}$ & 9,7 & 6,24 & 2,92 \\
\hline
\end{tabular}
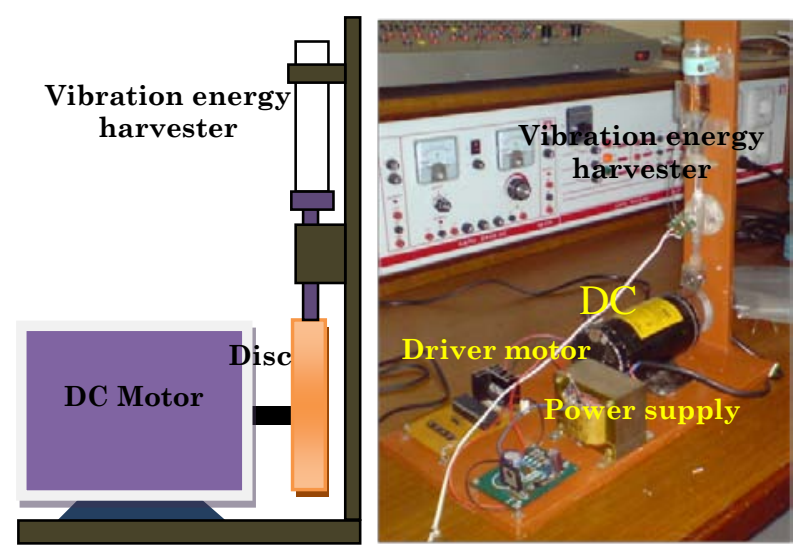

Figure 3. Schematic Diagram and the Experimental Apparatus

As shown in the tables, the $\mathrm{VEH}$ with various spring constants and magnetic fields or masses_were tested at various excitation frequencies and amplitudes. The output voltage and current was measured and compiled. The output power was then calculated based on the output voltage and current.

\section{Application on the KRI KKP-811's Engine}

Application of the prototype on the KRI KKP811's engine was done by employing the vibration energy harvester with maximum output power to 4 positions: (a) horizontal position; (b) vertical position; (c) base/foundation (at side position); and (d) base/foundation (at center position) as displayed in Figure 4. The output voltage and current of the VEH was measured using oscilloscope connected to output cable from the VEH as shown in the schematic diagaram in Figure 5 and the result was reported. The ouput voltage and current was recorded in the digital oscilloscope. The average voltage and current was calculated based on the recorded data where the average output power was calculated based on the average voltage and current. ardanat

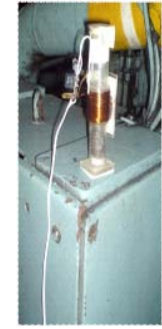

aHizotaPoxtion

adanet

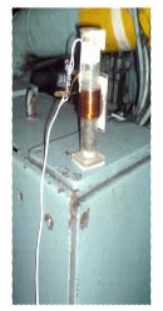

aHintapotion

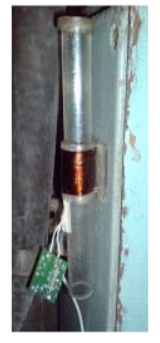

b Vétical Poxtion

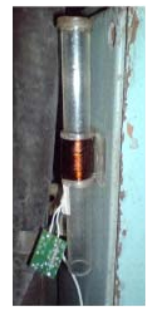

b TéticalPostion

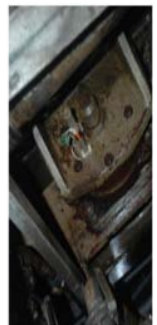

c. SdePcition

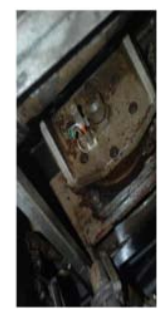

c.SckPotion

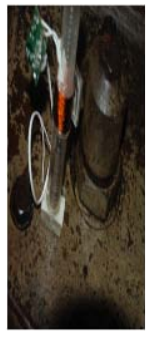

dCeterPosition)
Figure 4. Application of the Prototype on the KRI KKP-811's Engine
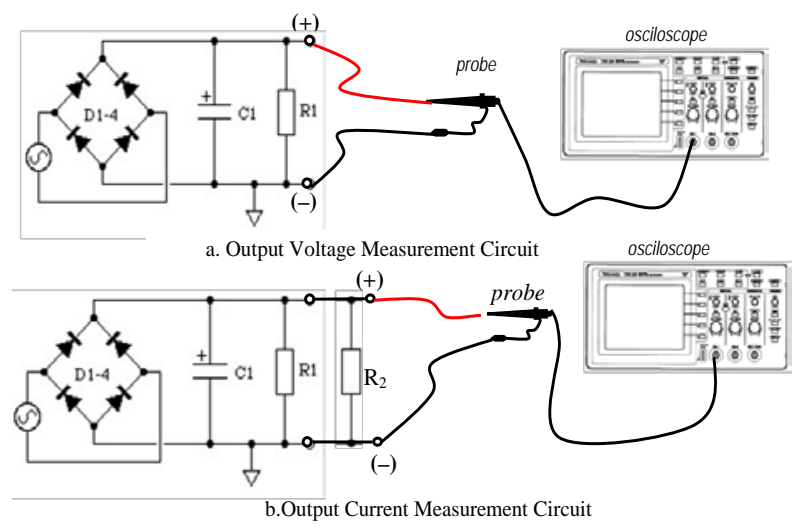

Figure 5. The Scheme of the Output Voltage and Current Measurement

\section{RESULTS AND DISCUSSION}

Figure 6 and 7 show the output voltage obtained from characterization of the vibration energy harvester for prototype I and II. The specification of prototype $\mathrm{I}$ is $k_{1}=11.84[\mathrm{~N} / \mathrm{m}], m_{2}=21.6 \times 10^{-3}[\mathrm{~kg}]$, $A_{2}=4 \times 10^{-3}[\mathrm{~m}]$ and $\omega_{4}=794[\mathrm{rpm}]$, whereas the specification of prototype II is $k_{1}=11.84[\mathrm{~N} / \mathrm{m}], m_{2}=$ $21.6 \times 10^{-3}[\mathrm{~kg}], A_{3}=6 \times 10^{-3}[\mathrm{~m}]$ and $\omega_{4}=484[\mathrm{rpm}]$. As shown in figure 6 and 7 , the output voltage and current are fluctuated as a function of time. The output voltage obtained from characterization were root mean squared for various $\mathrm{k}, \mathrm{m}, \mathrm{A}$ and $\omega$ using the following equation:

$\bar{V}=\sqrt{\left(\frac{\sum_{i=1}^{N} V_{i}^{2}}{N}\right)}$ 


$$
\bar{i}=\sqrt{\left(\frac{\left.\sum_{i=1}^{N}\left(V_{i} / R\right)^{2}\right)}{N}\right)}
$$

The root mean square of the voltage and current for various $\mathrm{k}, \mathrm{m}, \mathrm{A} \& \omega$ were compiled and summarized. Figure 8 and 9 show the root mean squared voltage and current for prototype III: $k_{1}=$ $11.84[\mathrm{n} / \mathrm{m}]$ and $36 \times 10^{-3}[\mathrm{~kg}]$ at various frequencies and amplitudes. The results show that in average, the higher the excitation frequency and amplitude, the higher the output voltage and current. In figure 9, especially for amplitude of $6 \mathrm{~cm}$ (A3), the data shows different trend/phenomena. It can be occur due to human error. Figure 10 and 11 shows the output voltage of the vibration energy harvester when it was applied to harvest the vibration energy of the KRI KKP-811's engine, at horizontal and vertical position. Figure 10 is the output voltage for horizontally placed vibration energy harvester and figure 11 is the output voltage for vertically placed vibration energy harvester. The horizontal and vertical placement of the vibration energy harvester can be seen in figure 4(a) and 4(b). (ditambahi table rata2 keluaran dayanya).

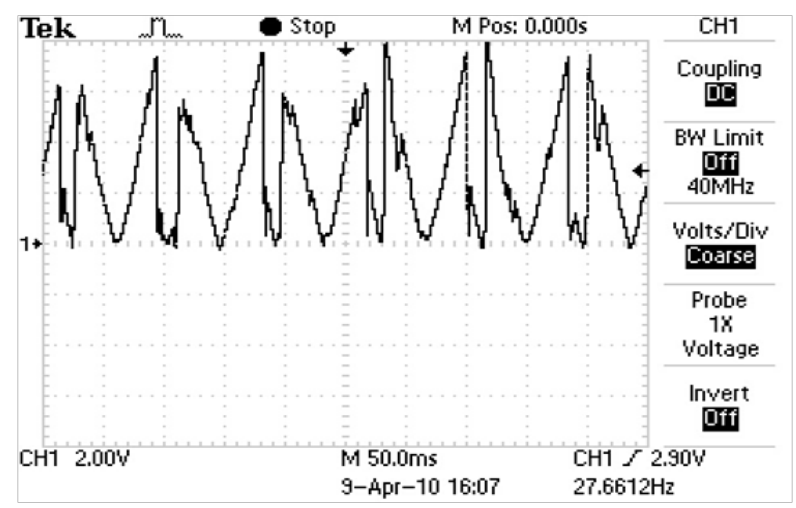

Figure 6. Output Voltage Obtained from Characterization for $k_{2}, m_{4}, A_{2} \& \omega_{4}$

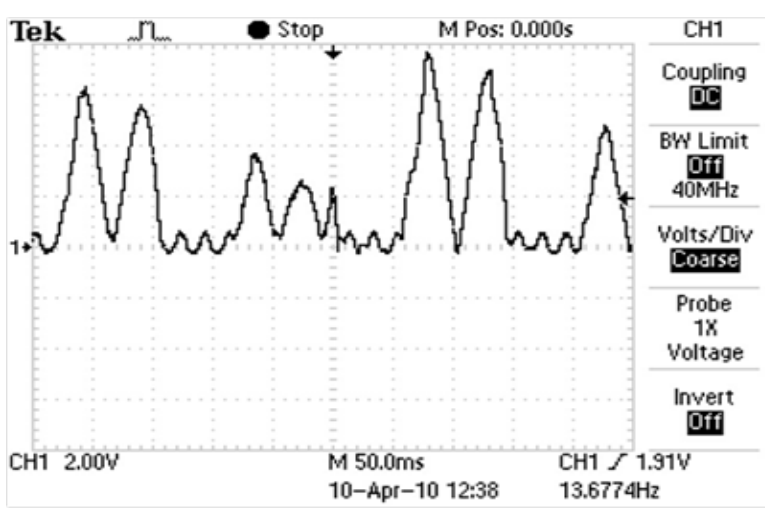

Figure 7. Output Voltage Obtained from Characterization for $k_{1}, m_{2}, A_{3} \& \omega_{2}$

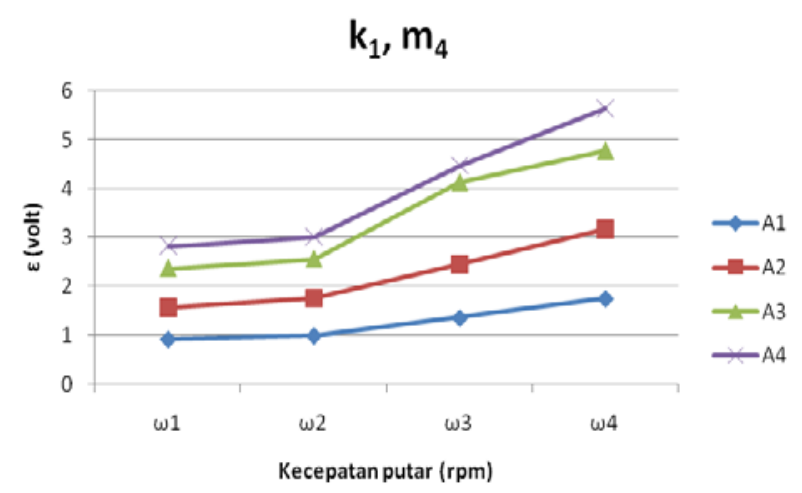

Figure 8. Output Voltage for Various Frequencies and Amplitudes $\left(\mathrm{k}_{1} \& \mathrm{~m}_{4}\right)$

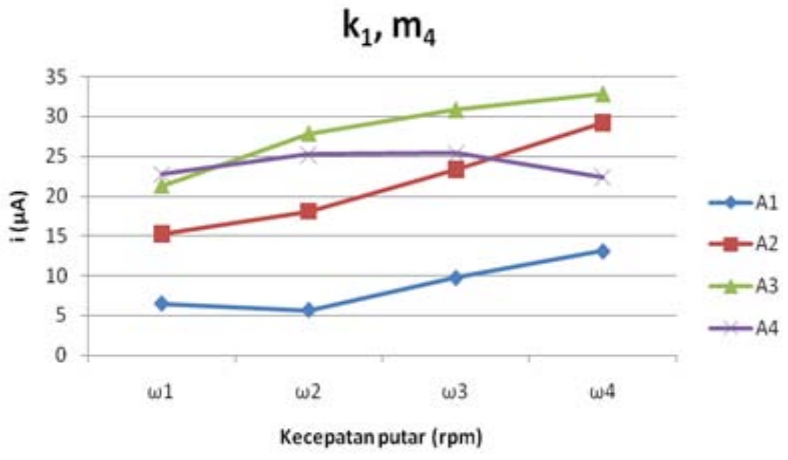

Figure 9. Output Current for Various Frequencies and Amplitudes $\left(\mathbf{k}_{1} \& m_{4}\right)$

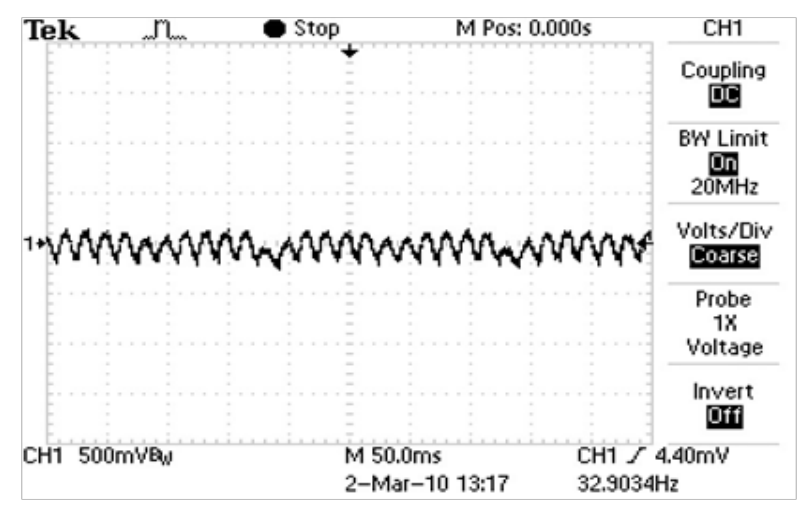

Figure 10. Output Voltage for Horizontally Employed Vibration Energy Harvester

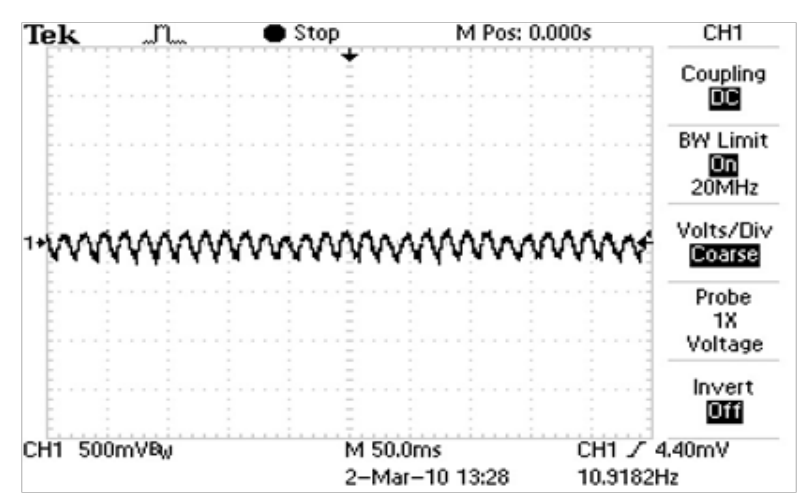

Figure 11. Output Voltage for Vertically Employed Vibration Energy Harvester 
Table 3. Output Power for Various Location of VEH at 500 rpm of Engine Speed

\begin{tabular}{ccccc}
\hline RPM & Location & $\begin{array}{c}\text { Erata-rata } \\
\text { (volt) }\end{array}$ & $\begin{array}{c}\text { i }_{\text {rata-rata }} \\
\text { (ampere) }\end{array}$ & $\begin{array}{c}\text { Daya } \\
\text { (watt) }\end{array}$ \\
\hline 500 & F (hor) & 0,05 & $4,05 \times 10^{-5}$ & $2,02 \times 10^{-6}$ \\
& F (ver) & 0,031 & $3,55 \times 10^{-5}$ & $1,1 \times 10^{-6}$ \\
& A & 0,019 & $2,14 \times 10^{-5}$ & $0,41 \times 10^{-6}$ \\
B & 0,015 & $1,82 \times 10^{-5}$ & $0,27 \times 10^{-6}$ \\
\hline
\end{tabular}

\section{CONCLUSION}

Vibration energy harvesting has been receiving a considerable amount of interest as a means of powering wireless sensors and low-power devices. In this paper, an energy harvester is presented to convert ambient mechanical vibration into electrical energy employing magnetoelectric generator. The harvester uses single magnet-spring attached on the coil. When the harvester is excited, the magnet moves relative to the coil, undergoes magnetic field variations and produces a power output. To obtain a maximum power output, the mass of magnet is varied. The magnetoelectric generator with various mass of magnets was tested by a harmonic exciter in various frequencies and amplitudes. The one with maximum power output was then applied to harvest the ambient vibration energy of KRI KKP-811's Engine. From characterization of the developed vibration energy harvester, the maximum output power of $160 \mathrm{\mu W}$ obtained for prototype with spring constant $k=13,14 \mathrm{~N} / \mathrm{m}$ and mass $m=36 \mathrm{~g}$ at disc frequency $\omega=794 \mathrm{rpm}$ and amplitude $A=6 \mathrm{~mm}$. This prototype was then applied to harvest vibration energy of the KRI KKP-811's engine and can generate maximum power of $2 \mu \mathrm{W}$ when it is placed at the base/foundation of the engine.

\section{REFERENCE}

1. S.P. Beeby, M.J. Tudor, N.M. White, Energy Harvesting Vibration Sources for Microsystems Applications, Meas. Sci. Technol. 17, R175-R195, 2006.

2. S.P. Beeby, R.N. Torah, M.J. Tudor, P. GlynneJones, T. O’Donnell, C.R. Saha, S. Roy, Micro Electromganetic Generator for Vibration Energy Harvesting, Micromech. Microeng. 17 (7). pp. 12571265, 2007.

3. M. El-Hami, P. Glynne-Jones, E. James, S.P. Beeby, N.M. White, A.D. Brown, J.N. Ross, M. Hill, Design and Fabrication of New Vibration of a New Vibration-based Electromechanical Power Generator, Sens. Actuators A 92, pp. 335-342, 2001.

4. P. Glynne-Jones, M.J. Tudor, S.P. Beeby, N.M. White, An Electromagnetic, Vibration-Powered Generator for Intelligent Sensor Systems, Sens. Actuators A 110, pp. 344-349, 2004.

5. C. Serre, A. Perez Rodriquez, N. Fondevilla, J.R. Morante, J. Montserrat, J. Esteve, Vibrational Energy Scavenging with Si Technology Electromagnetic Inertial Microgenerators, Microsyst. Technol. 13 (11/12), pp. 655-1661, 2007.

6. M. Mizuno, D. Chetwynd, Investigation of a Resonance Microgenerator, J. Micromech. Microeng. 13, pp. 209-216, 2003.

7. H. Kulah, K. Najafi, An Electromagnetic Micro Power Generator for Low-frequency Environmental Vibrations, in: Proceedings of the 17th IEEE Conference on Micro-Electro Mechanical Systems (MEMS), Maastricht, pp. 237-240, 2004. 